\title{
Procurement Reform and MIS Project Success
}

BY

\author{
Martyn R. Hulme
}

Martyn Hulme is the founder and president of HPH Consulting Services. Dr. Hulme earned his Ph.D. degree in cognitive psychology and human information processing from the University of Waterloo, and completed post-doctoral work in human factors engineering at the University of Michigan. His current projects include supporting Canadian federal and provincial government initiatives in procurement reform.

\section{IN BRIEF}

Less than one in 10 large Management Information System (MIS) projects succeeds. While the procurement process is not the only factor known to contribute to this high failure rate, it has been consistently identified as a source of difficulty. Knowing that procurement contributes to difficulty, however, is not useful if the reason it does so is not also known. This article analyzes procurement's contribution to failure, and describes the reforms needed to improve opportunities for success. The problem stems from the wide use of tender theory procurement (competitive bidding), and the invalid assumption that a specification can provide the basis for making value-oriented MIS buying decisions. In addition, tender theory procurement interacts with the MIS project environment to create an ethical hazard that makes it almost impossible to succeed. The reforms needed to overcome these problems are substantial. They require that tender theory be set aside and replaced by partnering-oriented procurement methods.

\section{INTRODUCTION}

n 1992, the United States General Accounting Office (GAO) reviewed Management Information Systems (MIS) projects and concluded:

Developing and modernizing government information systems is a difficult and complex process. Again and again, projects have run into serious trou ble, despite hard work by dedicated staff. They are developed late, fail to work as planned, and cost millions - even hundreds of millions - more than expected. The results, in missed benefits and misspent money, can be found throughout government. ${ }^{1}$

Failure is not confined to government. In 1994, the Standish Group presented these alarming statistics: only 16.2 percent of all MIS projects (less than 9 percent of large-company projects) are completed on time and within budget, with all required functions and features. Over 52 percent of projects are over budget, late, and offer fewer features and functions than originally specified. Almost one-third of projects (31.1 percent) are canceled. ${ }^{2}$ The cost of this failure is staggering. The Standish 
Group estimated that $\$ 81$ billion would be spent in 1995 by American organizations for canceled projects, and that an additional $\$ 59$ billion would be spent for late projects.

Until recently, MIS project failures attracted little systematic attention. Now, however, attention is turning to the causes of failure and the steps that must be taken to improve opportunities for success. Several reports have indicated that failure cannot be attributed to a single factor, and that improving opportunities for success will require action on several fronts. ${ }^{3}$

The purpose of this article is to:

- examine the role of procurement as a contributor to the failure of MIS projects

- provide an analysis of how procurement contributes to failure

- describe the procurement reform required to improve opportunities for success

It is not the contention of this article that procurement reform will, by itself, address all the issues that confront MIS projects. It is this author's contention, however, that procurement reform is vital, and unless it occurs, other necessary improvements will have limited impact on the overall success of MIS projects.

\section{PROCUREMENT'S ROLE AND CONTRIBUTION}

The procurement process has been consistently identified as a contributing factor to MIS project failures. ${ }^{4}$ Knowing that the procurement process contributes to failure, however, is not useful enough. The reasons for the failure must also be known.

Procurement's contribution to MIS project failure stems from several sources:

- Current MIS procurement processes are based largely on tender-theory procurement (competitive bidding).Tender theory is well established, widely practiced in public and private sectors, and has served both well. However, its strengths are also it weaknesses, and they create resistance to change. It is difficult for managers to understand how a process that has worked well for other goods and services could prove dysfunctional for MIS projects.

- Tender-theory procurement is specification oriented: a specification must be prepared before the procurement process can start, and this specification becomes an indispensable element in completing the process. Specifications, however, provide an objective basis for securing value only for some products. For others, such as MIS projects, specifications obstruct obtaining value.
- Finally, procurement processes based on tender theory interact with dysfunctionalities in the environment that characterize MIS projects; this creates an ethical hazard for the purchasing managers involved. Succumbing to this hazard intensifies the problems faced by MIS projects, making it almost impossible for them to succeed. Each of these problems is examined in more detail below.

\section{Tender-Theory Procurement}

Under tender theory, the purchasing organization first develops a specification concerning its requirements. It then calls for tenders to address the specification at a firm price. The bids submitted are evaluated for compliance to the specification. A contract is awarded to the supplier that meets the specification with the lowest-priced bid.

Although there are many variations of this basic method, they all involve specifications and a subsequent bid evaluation process that rates compliance to the specification. For MIS procurement, a request for proposal (RFP) is issued rather than a tender call. The RFP features a detailed specification of the MIS requirements, plus evaluation criteria for the specification.

The emphasis on the specification, and on rating compliance to the specification, stems from the desire to respect several principles, and a belief that a specification-oriented procurement process is the most satisfactory way of ensuring that this occurs. These principles include:

- best value

- competition

- fairness and accessibility

- transparency and openness

- prudence and probity $^{5}$

Tender-theory procurement easily satisfies the principles of competition, fairness and accessibility, transparency and openness, and, on the surface at least, prudence and probity. ${ }^{6}$ Does it also support attaining best value?

Answering this question requires an examination of best value, and the role of specifications in securing best value.

\section{BEST VALUE}

Securing best value is one of the cornerstones of procurement, and is emphasized particularly in government procurement. The concept may seem straightforward, but it is not.

Best value is not easy to establish, nor is it simply related to quoted price. Other factors besides price need to be assessed, and at times traded off, when trying to determine best value: quality, performance characteristics, the availability of service and follow-on support, the time required to 
deliver the good or service, and other situationspecific quantitative or qualitative elements. ${ }^{7}$

Tender-theory procurement attempts to address the complexities involved in assessing best value through the specifications. Thus, procurement specifications for MIS projects usually include a mix of quantitative and qualitative performance factors. It is essential that suppliers address these factors in their proposals.

This mandate is based on the assumption that the inclusion of such factors in the specification provides an objective basis for comparing competing proposals and identifying the supplier that will provide the best value. This assumption, however, is warranted only for certain types of products. The ability of a specification to provide an objective basis for assessing value varies across products. While specifications are essential to assessing value for products that are commodities, specifications cannot provide an objective basis for assessing value for products like custom-developed MIS application software.

\section{ROLE OF SPECIFICATIONS IN ASSESSING BEST VALUE}

Tender-theory procurement assumes that rating compliance to a specification provides an objective basis for assessing value when making a buying decision. This assumption is so ingrained that the typical response to dysfunctional procurement outcomes is to revisit the specification to determine what was left out, imprecise, or wrongly stated. This response has led to the development of increasingly complex and detailed specifications, developed in the belief that a specification can be written that will fully capture all important aspects of the requirement. Is this the right approach to take?

Consider the four broad classes of products that organizations now buy:

- commodities

- simple, durable goods

- complex custom-built goods

- complex, knowledge-based services

As the product being bought changes from a commodity to a complex, knowledge-based service, rating compliance to a specification provides a progressively less objective basis for selecting a supplier.

Rating compliance to a specification provides an objective basis for making a value-oriented decision when buying commodities. They can be graded according to clear, well-differentiated standards. It makes no sense to pay a premium for commodities that meet the same grading standard as lower-priced alternatives do. Selecting the supplier that offers the lowest-priced, compliant-tothe-specification commodity is the right decision.

Rating compliance can also help objectively determine the value of simple, durable goods made in commercial quantities. Each product's performance "out of the box" may be tested by measuring it against the specification, and the one that provides the best performance for a given price can be determined. That product's supplier is then selected.

Initial performance is not the only aspect of value for durable goods. Life-cycle performance also matters. For many durable goods, assessing actual life-cycle performance before they are bought is impossible. When actual performance cannot be known, it must be estimated.

As soon as estimated performance is allowed into the selection process, a step away from objectivity is taken. This can create a dilemma: To get best value, those making the selection decision may have to defend paying a higher price, about which there is no ambiguity, in order to ensure better estimated life-cycle performance, about which there is considerably uncertainty. It is not an easy decision to make or defend.

Rating compliance to a specification becomes less objective with complex, custom-built goods. The fundamental problem is that while there may be a detailed specification, during the procurement process there is nothing that can be objectively measured against it.

Most complex, custom-built goods are unique or few-of-a-kind items. Until the goods are built, all the prospective purchaser has is a supplier's promise to build a good that meets the specification. The purchaser must therefore estimate the relative probable value that will be obtained from different supplier promises, and select the supplier that appears to promise the best value. The process used to determine this may be painstaking, and is hardly as objective as measuring the performance of an existing good against a specification.

Rating compliance does not provide an objective basis for assessing the value of complex, knowledge-based services - the type of services brought for MIS projects - for two reasons.

First, complex, knowledge-based services exist only in the context of the supplier-client relationship. Until the relationship is established, there is only the supplier's potential to provide, and the client's potential to receive, the services. Like their complex, custom-built goods counterparts, such services do not exist in a measurable (or even experiential) form in advance of the selection decision. 
Second, the value of a complex, knowledgebased service depends on the quality of the relationship between the service's provider and its recipient. This relationship can never be precisely specified in advance; it is too creative and dynamic. Writing a specification for the relationship would require someone to define the terms and conditions associated with a constantly changing experience. It is simply not feasible.

As a result, for the complex, knowledge-based services brought to complete MIS projects, it is impossible to write a precise and detailed specification of the required services. Even if such a specification could be written, unless the client has previously experienced the supplier's service, there is nothing to measure against it. Therefore, what is being compared when tender theory is applied to MIS? The compliance of promises that cannot be experienced against requirements that cannot be stated. However painstakingly this comparison is done, it is not objective.

\section{DYSFUNCTIONALITIES IN THE MIS PROJECT ENVIRONMENT}

Tender-theory procurement's final contribution to the failure rate of MIS projects is the ethical hazard it creates. Procurement based on tender theory interacts with the environment that characterizes MIS projects to reinforce dysfunctionalities in project and risk management. These dysfunctionalities make it difficult to secure value under the best circumstances and intensify the problems facing MIS projects.

MIS projects and associated procurements take place in an environment characterized by the following:

- Lack of management continuity: Most large MIS projects are planned for completion over several years. During this time period, it is not unusual for there to be changes in management.

- An incentive system that encourages overly optimistic estimates of the benefits that can be attained from doing the project, and discourages realistic estimates of the costs that will be incurred: In addition, getting a project proposal approved requires developing a long-term project plan and milestone schedule. Planners know that the further one gets from the present date, the less likely it is that any event will occur as planned. Despite this, plans, once set, are difficult to change or even report progress against truthfully. As noted by the GAO:

"Because changes in plans and cost estimates are seen as indicators of poor management, project managers try to maintain a pretense of problem-free development and avoid providing honest assessments of project risks. By not mentioning problems for as long as possible, managers can often ensure continued project funding - at least in the near term ... Since agencies frequently change project managers, it becomes easy to defer problems to others. ${ }^{\prime 8}$

Tender-theory procurement interacts destructively with each of these factors.

Comprehensive specifications take time to complete. The time required to develop the specification in a form suitable for use in the procurement process delays the project, providing ample opportu-
In the early phases of the project, when the requirement is imperfectly understood and the objective of the phase is to develop understanding, procurement on a firm price basis is absurd. It is nevertheless routinely done. nity for changes in management and in the technology that may be appropriate to the project. Both factors add to the risk of failure.

MIS projects usually have several formal phases in which separate procurement processes are used to select the supplier to complete each phase. Phased procurement was originally introduced to reduce risk, and does to an extent. It also introduces opportunity to transfer problems to subsequent phases, and reinforces the tendency of those managing MIS projects to maintain a pretense of problem-free development and avoid providing honest assessments of project risks.

MIS specifications are developed progressively, over a series of phases, with each phase designed to progressively define the requirement. Often each phase is undertaken on the basis of contracts awarded using tender-theory procurement to select the supplier submitting the firm, lowestpriced bid to complete the work in a phase. In the early phases of the project, when the requirement is imperfectly understood and the objective of the phase is to develop understanding, procurement on a firm price basis is absurd. It is nevertheless routinely done.

When contracts are awarded in such a manner, the usual result is that the end of the attempt to develop an understanding of the requirement corresponds closely to the exhaustion of the firmprice budget for the phase. Whether this actually corresponds to the point at which the requirement is understood is another question. Frequently, both the client department and its supplier know it does not. Nevertheless, because there is pressure to be on time and within budget, this knowledge can be set aside, the phase can be declared closed, and the project can proceed to the next phase with the hope that anything left unresolved or unexplored can be addressed in the next phase.

This practice of declaring phases complete - and judging the specifications developed in them to be 
fully acceptable - can be repeated to maintain an illusion of steady progress and success, but only up to a point. Sooner or later the project's building phase arrives. At this critical point — the point at which there is no next phase - projects collapse. ${ }^{9}$

Despite this result, and despite the over 90percent failure rate of MIS projects, organizations persist in both applying tender-theory procurement to these projects, and in attempting to select suppliers on the basis of rating a supplier's promise to comply at the low-

Rather than securing best value, or even acceptable value, the attempt to commoditize the decision results in procurement processes that are costly to initiate, time consuming, and tend to result in adversarial relationships between clients and suppliers. est-cost to a specification. The question is why?

First, there is often a need, particularly in publicsector procurement, to be able defend the buying decision at the time it is made, even though the value, if any, that arises from the decision will not be realized until months or years later. The easiest defense is to point out that the supplier quoting the lowest contact price was the one selected.

Second is the specification orientation of the tender theory itself, and its erroneous logic of producing ever more detailed, lengthy, and costly specifications. The development of such lengthy and detailed specifications for MIS solutions is an attempt to "commoditize" the purchasing decision - to develop a specification that makes it possible to make the purchasing decision in the same way it is made for commodities, by awarding the contract to the supplier quoting the lowest price to meet the specification. This type of purchasing decision, however, cannot be commoditized. Rather than securing best value, or even acceptable value, the attempt to commoditize the decision results in procurement processes that are costly to initiate, time consuming, and tend to result in adversarial relationships between clients and suppliers. Neither party's requirements or expectations are satisfied, and significant time and cost overruns are the norm.

\section{IMPROVING OPPORTUNITIES FOR MIS SUCCESS}

As noted at the onset of this article, improving the success rate of MIS projects requires action on several fronts. In addition to reforming procurement, more attention must be given to the following areas:

- risk assessment during the initial planning

- project management once a project is underway

- risk management during the subsequent execution of the project

With regard to improving procurement, it is clear that the necessary improvements will entail more than modest refinements to existing processes. The flaws in tender-theory procurement are, for MIS procurement, fundamental. Merely trying to expedite the process, in the belief that the processes are too slow to keep pace with rapidly changing technology, will not be sufficient.

The type of reform that is needed will appear radical to many. Tender-theory procurement, and the use of specifications as the basis for making the purchasing decision, must be set aside for MIS projects. ${ }^{10}$ If tender theory is to be set aside, what will replace it?

\section{Partnering-Oriented Procurement}

A promising method of procurement that has been pilot tested and selectively implemented is establishing longer-term "partnering" relationships between suppliers and their clients. This method focuses on the business problem to be solved and supplier qualifications with regard to that problem - rather than on the development of detailed specifications for a solution. This method includes:

- Accelerated supplier selection. Unlike tender-theory procurement, in which the supplier selection process can last for months or years, these methods have supplier selection processes that typically take no more than several weeks.

- Lower cost for both suppliers and clients to complete the supplier selection process. Tens, possibly hundreds, of thousands of dollars may easily be spent in procurement initiation activities such as creating the specification required to move forward with tender-theory procurement. These new methods feature requests for proposals that are 20 to 30 pages in length, and require that proposals not exceed that length.

- No specifications. These methods proceed from a statement of the business problems to be solved. This is all. There is no specification. There is no description of the solution required. There is not even a statement of work. There are only statements of the problem, the qualifications being sought in the supplier "partner," and of the basis upon which prospective supplier "partner" will be assessed.

- Relinquishing the objective of trying to secure the lowest possible price. Tender theory's lowcost, compliant-to-the-specification model of value is viewed as both unrealistic and unattainable, and as having contributed to corrosive relations between suppliers and clients that serve neither party's interests over the life of the MIS solution. These methods focus, instead, on a price that both parties can be satisfied is reasonable given the nature of the problem, the risks involved in solving it, and the benefits that will accrue from a solution. 
If this sounds too good to be true, it is important to note the following:

- The agreements negotiated as a result of these methods tend to have much greater complexity, and are more challenging to establish than contracts struck under tender-theory procurement. One reason for this is that these methods seek to establish alliances between suppliers and client departments in which both risks and rewards are shared.

- The process is also a more demanding process for all the participants. Although tender-theory procurement involves hard work, as a process it is essentially routine. These new methods represent such a fundamental change in orientation that they require a major change in attitudes. Often, attitude change of this magnitude will only be forthcoming if there is a high degree of commitment to the method among all stakeholders in the MIS solution.

One example of this process is now in use in the Province of Nova Scotia. Developed in the summer of 1994, it is known as Cooperative Business Solutions (CBS). In late 1995, the Province of Ontario launched its own variant, Common Purpose Procurement. Both programs are refinements and extensions of an experimental procurement method developed for the Canadian federal government by a joint industry/government working group.

\section{CONCLUSIONS}

There are complex interdependencies among the factors that contribute to the success of MIS projects. Improving the opportunities for success of these projects, therefore, requires action on a number of fronts. This includes reform aligned to the implementation of a partnering-oriented approach to procurement on MIS projects.

However, no one action - for example, changing procurement methods - is going to produce a quantum jump in the probability of success. By the same token, failure to take action on all fronts, including procurement reform, will significantly constrain opportunity for success.

It is difficult to overemphasize this last point. There is ample evidence that even when strong project management is applied to an MIS project, it will not recover the project from the problems that stem from using tender-theory procurement to select a supplier. ${ }^{11}$ Likewise, the Canadian federal government's pilot of a partnering-oriented procurement method, Common Purpose Procurement, revealed that a procurement method unsupported by strong project and risk management can also lead to project failure. The required reforms must go hand in hand.

\section{REFERENCES}

1. "Information Management and Technology Issues," United States General Accounting Office, Office of the Comp troller General, Report No.: GAO/OCG-93-5TR, p. 2.

2. "Chaos: Charting the Seas of Information Technology," A Special COMPASS Report, The Standish Group International, Inc. Dennis, MA, p. 2.

3. See, for example, "Methods of Supply for IT/SI Projects: A Comparative Assessment," Public Works and Govern ment Services Canada, Ottawa, Canada, 1995, pp. 23-25.

4. See, for example, "Information Management and Technology Issues," United States General Accounting Office, Office of the Comptroller General, Report No.: GAO/OCG93-5TR, p.5-6; "Alternatives to Grand Design for Systems Modernization," Information Resources Management Services, U.S. General Services Administration, 1991, pp. 27-32; "Managing the Risk and Uncertainty of Technological Change, A Review of Federal practices for Acquiring major Information System," President's Coun cil on Management Improvement, 1990, pp 10-11.

5. Reference to these principles is incorporated in various policy manuals used by governments. At the Canadian federal government level, the Treasury Board Contracting Manual and the Public Works and Government Services Canada Supply Policy Manual both espouse adherence to these principles.

6. See, for example, the analysis provided in "Methods of Supply for IT/SI Projects; A Comparative Assessment," Public Works and Government Services Canada, Ottawa, Canada, 1995, pp. ii-iii.

7. In Canadian government procurement these can include economic, regional, and industrial development incentives, as well as other social policy objectives.

8. "Information Management and Technology Issues," Unites States General Accounting Office, Office of the Comp troller General, Report No.: GAO/OCG-93-5TR, p.7.

9. The tendency for projects to be on time and on budget right up to the moment when they fail catastrophically is endemic in government information technology projects.

10. It is vital not to confuse two related points concerning the role of specifications in MIS. This article contends that specification-oriented procurement is not appropriate for large-scale MIS: that it does not provide a reliable basis for selecting a supplier. This is not to say that specifications are irrelevant in systems development. Once a supplier has been selected, it will be important for the supplier to work with its client to develop an understanding of the requirement, and from it, to develop design and programming specifications from which the system can be built.

11. "Information Management and Technology Issues," United States General Accounting Office, Office of the Comp troller General, Report No.: GAO/OCG-93-5TR, p.6. 